\title{
Morphometry of Human Placenta in Natural Conception and Assisted Reproduction with its Clinical Significance
}

\author{
Ananthi $\mathrm{V}^{1}$, Rajkumar $\mathrm{D}^{2}$, Muniappan $\mathrm{V}^{3}$ \\ ${ }^{1}$ Tutor, Department of Anatomy, Rajah Muthiah Medical College, Annamalai University, Chidambaram, ${ }^{2}$ Dean, Faculty of Medicine, Rajah Muthiah Medical \\ College, Annamalai University, Chidambaram, ${ }^{3}$ Professor and Head, Department of Anatomy, Rajah Muthiah Medical College, Annamalai University, \\ Chidambaram.
}

\section{Abstract}

Introduction: Placenta is a mirror which reflects the antepartum status of fetus in utero. Our present study aimed to analyse the morphometry of placenta in normal and assisted reproduction. Subjects and Methods: 30 Placentas of natural conception and 42 placentas of assisted reproduction (18 cases of singleton pregnancies, 12 cases of twin pregnancies) were collected from OG department, Rajah Muthiah Medical College and from private fertility centre in and around Chidambaram immediately after delivery. Morphometric dimensions of placenta like thickness, diameter, area, number of cotyledons were measured placental weight, fetal weight were also measured. Results: Placental weight of natural conception was $489 \pm 107.84$ grams, $316.78 \pm 88.24$ grams in assisted reproduction. Thickness of placenta was $2.767 \pm 0.68 \mathrm{~cm}$ in natural conception, $1.78 \pm 0.68 \mathrm{~cm}$ in assisted reproduction. Number of cotyledons, fetal weight, feto - placental ratio were also reduced in assisted reproduction. Conclusion: This is the first study to analyse the morphometric dimensions of placenta in natural conception and in assisted reproduction. Overall there was a reduction in all dimensions of placenta in assisted reproduction. This will be useful for pediatricians who handle the newborns of assisted reproduction.

Keywords: Assisted Reproduction, Placenta, Morphometry, Feto-Placental Ratio.

Corresponding Author: Dr. Rajkumar D, Dean, Faculty of Medicine, Rajah Muthiah Medical College, Annamalai University, Chidambaram.

Received: September 2019

Accepted: September 2019

\section{Introduction}

The placenta is the principle site of nutrient and gas exchange between mother and fetus, It acts as a mirror which reflects the fetal outcome. The placenta and fetal membranes perform special functions like protection, nutrition, respiration excretion and hormone production. It has two components

i. The fetal portion is formed by villous chorion

ii. The maternal portion is formed by deciduas basalis, the part of decidua (Uterine endometrium) which is related to the fetal component of the placenta. ${ }^{[1]}$

The placenta is generally attached to the posterior wall of uterus near fundus. The site of attachment is determined by the point where the blastocyst becomes embedded. The maternal surface of the placenta is finely granular and mapped into some $15-20$ lobes by series of fissures of grooves(fig 1). The lobes are otherwise known as cotyledons. This maternal surface is also referred as "Dirty Duncan". Fetal surface is smooth, covered by amnion with umblical cord attachment(fig 2). It is otherwise known as "placental Roof or Shini-Scbultze". [2]

The umblical cord is generally attached near the centre of the fetal surface and branches of the umblical vessels radiate out under the amnion from this point; the veins being deeper and larger than the arteries. There are many pathological form of placental adherence which includes accrete, increta, percreta.

The placenta is a flattened discoid mass. It may be circular or oval in shape. It has an average weight of $470 \mathrm{~g}$, an average diameter of $18.5 \mathrm{~cm}$, and an average thickness of 23 $\mathrm{mm}$. It is thick at centre, thin at periphery. ${ }^{[3]}$ The total number of cotyledons remain same throughout the gestation, but individual cotyledons continue to grow till term by Crawford. $^{[4]}$

\section{Assisted Reproduction \\ Assisted reproduction is a technique, where the gametes are manipulated artificially and fertilized embryo can be re- inserted into the mother's womb. \\ Assisted reproductive technique (ART) is an inestimable gift to the infertile couple those who exhausted by trying various infertility treatments. But there are many fall-outs in ART newborns like pre term birth, low birth weight, genetic disorders etc,. There are various methods in ART like Invitro fertilization (IVF), Gamete Intrafallopian transfer (GIFT), Intracytoplasmic sperm injection (ICSI).In our present study, we have collected the placentas from ICSI technique followed cases. Most of the cases in IVF}


pregnancies are twin babies, the placentas and fetal membranes in those cases are Diamniotic Dichorionic [Figure 3].

\section{Intracytoplasmic Sperm Injection}

Spermatozoa sometimes fails to fertilize even when they are artificially placed in close proximity to eggs during conventional in vitro fertilization(IVF).Fertilization failure in IVF is particularly common where there are gross abnormal semen parameters or number of spermatozoa is insufficient. The placing of spermatozoan beneath the zona has yielded consistent results. The Intracytoplasmic sperm injection procedure entails the deposition of single spermatozoan directly into the cytoplasm of the oocyte, thus bypassing the zona pellucida and oolemma. ${ }^{[5]}$

Our present study aimed to analyse the morphometric parameters of placenta in natural conception and in assisted reproduction.

\section{Subjects and Methods}

30 Placentas of natural conception and 42 placentas of assisted reproduction (out of 42, 18 cases are singleton pregnancies, 12 cases are from twin pregnancies) were collected from OG department, Rajah Muthiah Medical College and Hospital and from Private Fertility Centre in and around Chidambaram. Human ethical committee clearance was obtained before sample collection .Placentas were washed in running tap water to remove blood clots .Fetal surface and maternal surface were examined for placental cysts, calcification, Infarction, Membranes were trimmed and placental weight were measured using electronic weighing machine. Thickness of placenta, diameter of placenta was measured using measuring tape, metal ruler and compass. Maternal surface was examined and cotyledons number were counted [Figure 1]. Fetal weight was measured using electronic weighing machine. Feto placental ratio was calculated. Area of placenta was also calculated using diameter values.

Statistical Analysis:

Statistical analysis was performed using SPSS. The data obtained from the study was complied and expressed as mean \pm standard deviation. Mann - whitney test were performed. Two tailed t- test was done $\mathrm{z}$ values are also tabulated. $\mathrm{P}$ value of $<0.05$ was taken as significant.

\section{Results}

Table 1: Clinical findings of natural conception and assisted reproductive pregnancies

\begin{tabular}{|l|l|l|l|}
\hline S.No & $\begin{array}{l}\text { Clinical } \\
\text { Parameters }\end{array}$ & Normal (mean) & ART(mean) \\
\hline 1 & Maternal age & 28.33 & 32.93 \\
\hline 2 & Gestational age & 37.03 & 36.16 \\
\hline 3 & Mode of Delivery & Caesarean & Caesarean \\
\hline 4 & HB & 11.07 & 11.77 \\
\hline 5 & APGAR Score & $9 / 10$ & $8 / 10$ \\
\hline
\end{tabular}

maternal age of assisted reproduction when compared to natural conception [Table 1].Gestational age reduced in assisted reproduction [Table 1].

Table 2: Morphometric findings of Placenta
\begin{tabular}{|l|l|l|l|l|l|}
\hline S.No & Parameters & $\begin{array}{l}\text { Normal } \\
\text { Mean } \pm \\
\text { Std. } \\
\text { Deviation }\end{array}$ & $\begin{array}{l}\text { ART: } \\
\text { Mean } \pm \\
\text { Std. } \\
\text { Deviation }\end{array}$ & $\begin{array}{l}\text { Z } \\
\text { Value }\end{array}$ & $\begin{array}{l}\text { P } \\
\text { Value }\end{array}$ \\
\hline 1 & $\begin{array}{l}\text { Thickness of } \\
\text { Placenta (cm) }\end{array}$ & $\begin{array}{l}2.767 \pm \\
0.679\end{array}$ & $\begin{array}{l}1.781 \pm \\
0.681\end{array}$ & 5.27 & 0.000 \\
\hline 2 & $\begin{array}{l}\text { Diameter of } \\
\text { Placenta }(\mathrm{cm})\end{array}$ & $\begin{array}{l}18.233 \pm \\
2.763\end{array}$ & $\begin{array}{l}16.881 \pm \\
2.287\end{array}$ & 1.977 & 0.048 \\
\hline 3 & $\begin{array}{l}\text { Area of } \\
\text { Placenta } \\
\left(\mathrm{cm}^{2}\right)\end{array}$ & $\begin{array}{l}266.79 \pm \\
83.23\end{array}$ & $\begin{array}{ll}227.70 \pm \\
60.61\end{array}$ & 1.732 & 0.083 \\
\hline 4 & $\begin{array}{l}\text { No. of } \\
\text { Cotyledons }\end{array}$ & $\begin{array}{l}13.967 \pm \\
2.773\end{array}$ & $9.714 \pm$ & 5.595 & 0.000 \\
\hline P<0.05 is significant & & & & \\
\hline
\end{tabular}

Table 3: Placental and Fetal weights of two groups

\begin{tabular}{|l|l|l|l|l|l|}
\hline S.No & Parameters & $\begin{array}{l}\text { Normal } \\
\text { Mean } \pm \\
\text { Std. } \\
\text { Deviation }\end{array}$ & $\begin{array}{l}\text { ART } \\
\text { Mean } \pm \\
\text { Std. } \\
\text { Deviation }\end{array}$ & $\begin{array}{l}\text { Z } \\
\text { Value }\end{array}$ & $\begin{array}{l}\text { P } \\
\text { Value }\end{array}$ \\
\hline 1 & $\begin{array}{l}\text { Placental } \\
\text { weight } \\
\text { gms) }\end{array}$ & $489 \pm 107$ & $\begin{array}{l}316.78 \pm \\
88.21\end{array}$ & 5.73 & 0.0000 \\
\hline 2 & $\begin{array}{l}\text { Fetal weight } \\
\text { (kgs) }\end{array}$ & $\begin{array}{l}2.92 \pm \\
0.45\end{array}$ & $\begin{array}{l}2.417 \pm \\
0.56\end{array}$ & 3.693 & 0.0000 \\
\hline 3 & Feto- & $6.15 \pm$ & $\begin{array}{l}8.127 \pm \\
2.89\end{array}$ & 3.524 & 0.0000 \\
& $\begin{array}{l}\text { Placental } \\
\text { ratio }\end{array}$ & 1.223 & & & \\
\hline
\end{tabular}

$\mathrm{P}<0.05$ is significant

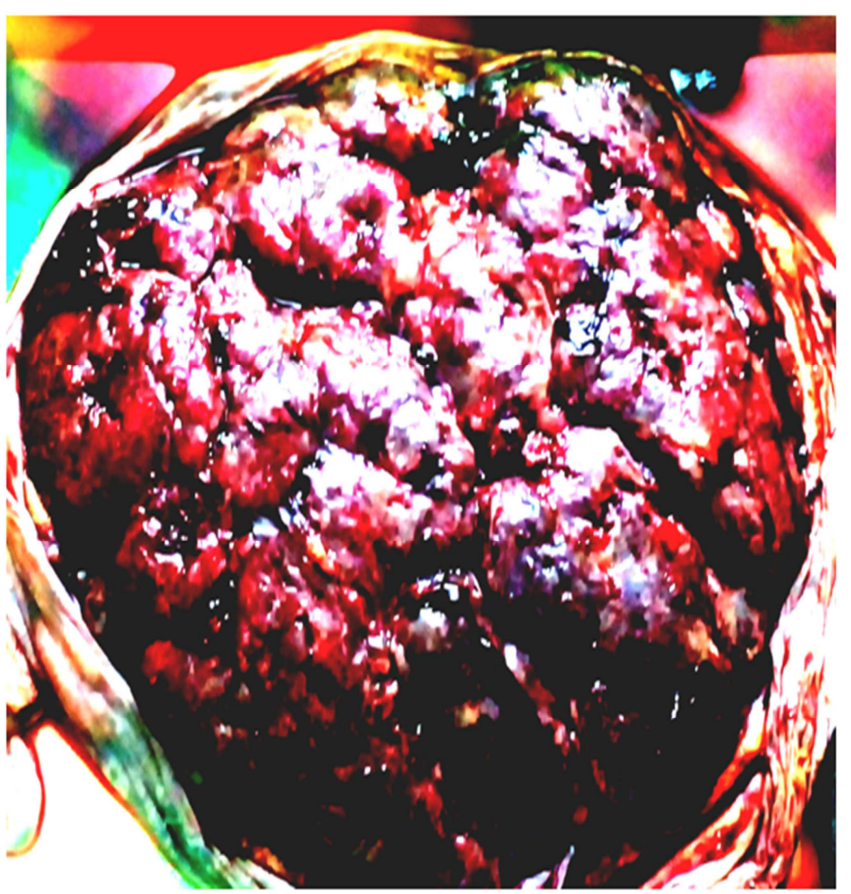

Figure 1: Maternal Surface of Placenta with Cotyledons.

Thickness, Diameter and area of placenta were measured; number of cotyledons was also counted. Fetal weight, placental weight and feto-placental ratio were also measured and tabulated. There was a significant increase in the 


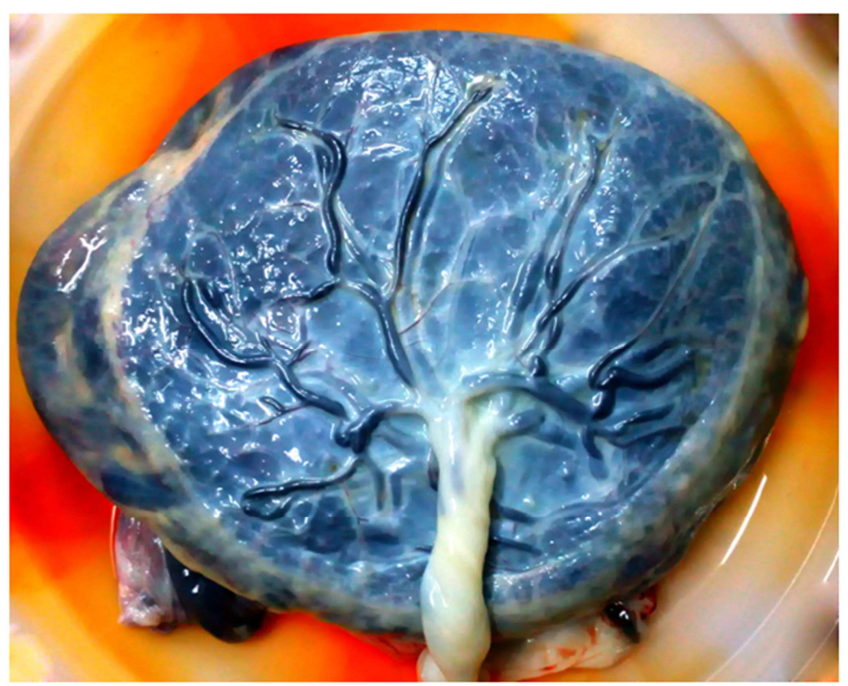

Figure 2: Fetal Surface of Placenta with Radiating Umblical Vessels.

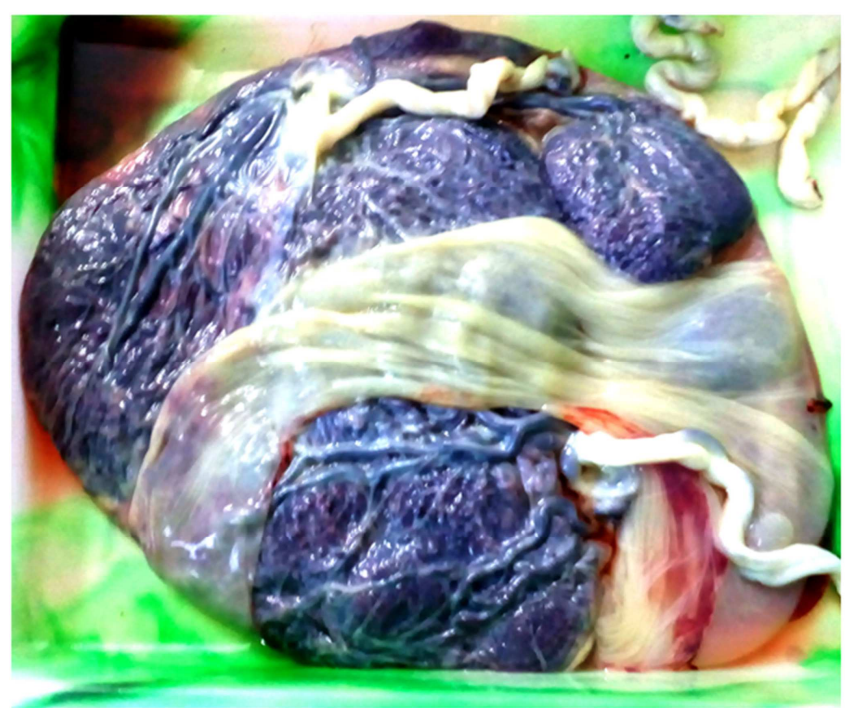

Figure 3: Placenta of Twin Pregnancy with Double Umblical Cord.

\section{Discussion}

Placenta is a leading cause of maternal and perinatal mortality. ${ }^{[6]}$ Placenta reflects the most accurate record of prenatal life of an infant; it undergoes many changes in its dimension throughout the gestation. ${ }^{[7]}$

The intrauterine growth and survival of fetus is dependent on placenta. It is a feto - maternal organ shares the same stress and strain, to which the fetus is exposed. So any diseases affecting the mother and foetus, also affects the placenta.

According to Ambedkar Raj Kulandaivelu et al, ${ }^{[8]}$ the mean thickness of placenta was $1.42 \mathrm{~cm}$, thickness was reduced in Pregnancy Induced Hypertension (PIH). In our present study, the mean thickness of placenta was $2.767 \pm 0.679 \mathrm{~cm}$ in Natural conception, $1.781 \pm 0.681 \mathrm{~cm}$ in assisted reproduction [Table 2].

According to Michel Yampolsky et al, ${ }^{[9]}$ abnormality of the placental vasculature affects the placenta thickness, resulting in a small baby for given placental weight.

In Udaina $\mathrm{A}$ and Jain ML et al, ${ }^{[10]}$ mean weight of placenta was 495 grams in control group, 435 grams in mild PIH cases, 371.43 grams in severe PIH group. In our present study the mean weight of placenta was 489 grams in Natural conception, 316.78 in Assisted reproduction [Table 3].

According to Hosemann et al, ${ }^{[11]}$ in normal term pregnancy the mean placental weight was $400-1000$ grams, where as Wigglesworth et al, ${ }^{[12]}$ found placental weight to be 360 570 grams. In our present study the mean placental weight was $489 \pm 107$ grams in Natural conception, $316 \pm 88.24$ grams in assisted reproduction. There was a significant reduction in the placental weight of assisted reproduction. These changes may affect the fetal growth indirectly.

The examination of placenta in utero as well as postpartum provides much insight into the prenatal growth of the infant and mother. ${ }^{[13]}$

In Gunapriya et al, ${ }^{[14]}$ paucity of cotyledons was noted in $\mathrm{PIH}$ cases. In our present study, number of cotyledons was significantly reduced in assisted reproduction when compared to natural conception [Table 2].

According to Chakravorthy et al, ${ }^{[15]}$ mean placental weight of 410 grams in mild hypertension, 350grams in severe hypertension. The transverse diameter of placenta was significantly reduced in pre eclampsia group by Teasdale et al, ${ }^{[16]}$ in our present study the mean diameter of placenta was $18.23 \pm 2.76 \mathrm{~cm}$ in Natural conception $16.88 \pm 2.28 \mathrm{~cm}$ in assisted reproduction [Table 2]. There was a significant reduction in the placental diameter in assisted reproduction. In cibils et al, ${ }^{[17]}$ placentas from hypertensive patients were significantly smaller than the normal.

In Kotgirwar et al, ${ }^{[18]}$ there was a significant reduction in the feto - placental ratio and placental dimensions in case of idiopathic intrauterine growth retardation. In the present study, feto-placental ratio was 6.149:1 in Natural conception, 8.13:1 in assisted reproduction [Table 3]. These results were varied from previous studies.

In the present study mean area of placenta was $266.76 \pm$ $83.23 \mathrm{~cm}^{2}$ in Natural conception, $277.70 \pm 60.61 \mathrm{~cm}^{2}$ assisted reproduction [Table 2].

We concluded that there was a significant reduction in the dimensions of placenta in assisted reproduction. Fetoplacental ratio was increased in assisted reproduction.

To the best of our knowledge, this is the first study to analyze the morphometric dimensions of placenta in assisted reproduction in our Indian population.

\section{Conclusion}

Our present study results showed that there was a significant reduction in all the dimensions of placenta in assisted reproduction. These placental maldevelopment may affect the fetal growth and development. These results would be useful for Neonatologists who handle the newborns of ART mothers. These results would be useful for obstetrician and gynecologists who handle infertile cases.

\section{References}

1. Moore K.L, Persuad T.V.N. Female reproductive system. In: 
Susan standring, editor. Gray's anatomy, $39^{\text {th }}$ Edition. Churchill Livingstone; 1989: P 1341-49.

2. Ian Rushton. Placenta as a reflection of maternal disease. In Eugene V.D.K.Perrin,editor. The pathology of placenta. $1^{\text {st }}$ Edition. New York;Churchill Livingston;1984:P 57-84.

3. Moore K L, Persuad T.V.N. Placenta and Fetal Membranes. In: Moore \& Persaud, editor. The Developing Human Clinically oriented embryology, $7^{\text {th }}$ Edition. Saunders; 2003: P 120-32.

4. Crawford I.M. A study of Human placental growth with observations on the placenta in Erythroblastosis foetalis .Journal of Obstetrics and Gynaecology of British Empire; 1959: Vol LXVI.No.6.

5. Toru Suzuki and Anthony C.F. PerryIntracytoplasmic injection (ICSI): Applications and Insights.In :Palermo,Gianplero.D,Sills E.Scott,editor. Intra cytoplasmic Sperm Injection,Springer, New York ;2018.

6. Roberts J.M, Cooper DW. Pathogenesis and genetics of preeclampsia.The Lancet 2001: 357.Issue.9249.P 53-6.

7. Pradeep S,Londhe, Abhay B, Mane. Morphometric study of placenta and its correlation in normal and hypertensive pregnancies.Int J of Pharma and Biosci; 2011: 2(4): P 429-32.

8. Ambedkar Raj Kulandaivelu, Banushree C. Srinivasamurthy, Anushree Murugan, A.Mutharasu. Morphology and Morphometric Study of Human Placenta in Rural Southern India. British Journal of Medicine \& Medical Research; 2014: 4(15): P 2995-3008.

9. Michel Yampolsky, Cardy M.Salafia, Oleksandr Shlakhter, Danielle Haas, Barbara Eucker, John Thorp. Abnormality of the
Placental vasculature affects placental thickness.Quantitative Biology.arxiv:1101.1892.

10. Udainia, A; Jain, M.L. Morphological Study of Placenta in Pregnancy Induced Hypertension With its Clinical Relevance. J Anat. Soc. India; 2001: 50(1) .P 24-27.

11. Hosemann.H. Duration of pregnancy and weight of the placenta.Archives of Gynecology; 1946: P 176-453.

12. Wigglesworth J.S.The Gross and Microscopic pathology of the Prematurely Delivered Placenta.BJOG; 1962: 69.P 934-43.

13. kouvalainen K,Pynnonen AI, Kaarainen M, Peltonen T. Weights of Placenta,Fetal membranes and Umblical Cord.Duodecim;1971:87(17).P 1210-1214.

14. Gunapriya Raghunath, Vijayalakshmi, varsha shenoy. A Study on the Morphology and the Morphometry of the Human Placenta and itsClinical Relevance in a population in Tamilnadu. Journal of Clinical And Diagnostic Research; 2011:Vol 5(2).P 282-86.

15. Chakravorthy A.P. Foetal and Placental Weight changes in Normal Pregnancy and Pre-eclampsia.BJOG; 1967:74. P 247-53.

16. Teasdale F.Gestational changes in the functional structure of the human placenta in relation to fetal growth: A morphometric study.Am J Obstet Gynaecol; 1980: Vol .137, Issue 5, P 560-68.

17. Cibils.L A.The placenta and newborn infant in hypertensive conditions. Am J Obstet Gynaecol; 1974:118(2).P 256-70.

18. Kotgirwar.S, Ambiye.M, Athavale.S, Gupta.V, Trivedi.S. Study of Gross and Histological Features of Placenta in Intrauterine Growth Retardation. J Anat. Soc. India; 2011: Vol 60.Issue 1.P $37-40$.

Copyright: () the author(s), publisher. Academia Anatomica International is an Official Publication of "Society for Health Care \& Research Development". It is an open-access article distributed under the terms of the Creative Commons Attribution Non-Commercial License, which permits unrestricted non-commercial use, distribution, and reproduction in any medium, provided the original work is properly cited.

How to cite this article: Ananthi V, Rajkumar D, Muniappan V. Morphometry of Human Placenta in Natural Conception and Assisted Reproduction with its Clinical Significance. Acad. Anat. Int. 2019;5(2):42-45.

DOI: dx.doi.org/10.21276/aanat.2019.5.2.12

Source of Support: Nil, Conflict of Interest: None declared. 